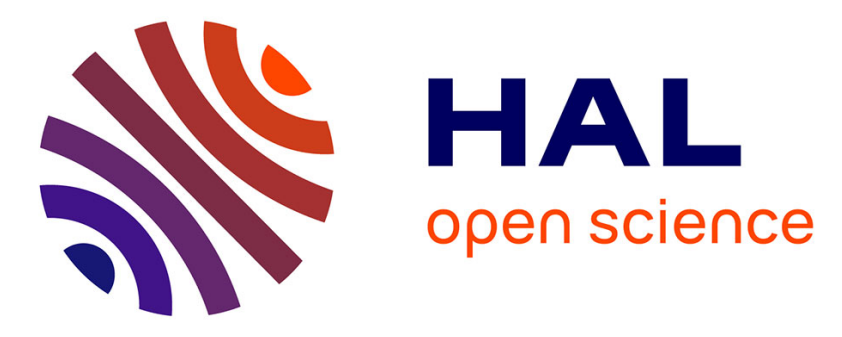

\title{
L'institutionnalisation des politiques culturelles en Europe du sud: éléments pour une approche comparée
}

Vincent Dubois, Emmanuel Négrier

\section{To cite this version:}

Vincent Dubois, Emmanuel Négrier. L'institutionnalisation des politiques culturelles en Europe du sud: éléments pour une approche comparée. Pôle Sud - Revue de science politique de l'Europe méridionale, 1999, Les politiques culturelles en Europe du Sud., 10, p. 3-9. 10.3406/pole.1999.1028. halshs-00502484

\section{HAL Id: halshs-00502484 \\ https://shs.hal.science/halshs-00502484}

Submitted on 21 Apr 2020

HAL is a multi-disciplinary open access archive for the deposit and dissemination of scientific research documents, whether they are published or not. The documents may come from teaching and research institutions in France or abroad, or from public or private research centers.
L'archive ouverte pluridisciplinaire HAL, est destinée au dépôt et à la diffusion de documents scientifiques de niveau recherche, publiés ou non, émanant des établissements d'enseignement et de recherche français ou étrangers, des laboratoires publics ou privés.

\section{(ㅇ)(1) $\$$}

Distributed under a Creative Commons Attribution - NonCommercial - NoDerivatives| 4.0 


\section{L'institutionnalisation des politiques culturelles en Europe du Sud :} éléments pour une approche comparée

Mr Vincent Dubois, Mr Emmanuel Négrier

\section{Citer ce document / Cite this document :}

Dubois Vincent, Négrier Emmanuel. L'institutionnalisation des politiques culturelles en Europe du Sud : éléments pour une approche comparée. In: Pôle Sud, n¹0, 1999. Les politiques culturelles en Europe du Sud. pp. 5-9;

doi : https://doi.org/10.3406/pole.1999.1028

https://www.persee.fr/doc/pole_1262-1676_1999_num_10_1_1028

Fichier pdf généré le 23/04/2018 


\title{
L'institutionnalisation des politiques culturelles en Europe du Sud :
} éléments pour une approche comparée

\author{
par Vincent Dubois \\ IEP Strasbourg \\ et Emmanuel Négrier \\ CEPEL/CNRS
}

Pôle Sud $N^{\circ} 10$ - mai $1999-p .5$ à 9

\section{"Européanisation" et comparai- son des politiques culturelles'}

L'affirmation, fût-elle récente et encore timide, d'une politique culturelle de l'Union européenne permet de risquer l'hypothèse : le traitement public des affaires culturelles connaît de plus en plus le processus général dit d'européanisation" des politiques nationales. Certes, tout comme l'édification d'une "Europe de la culture", cette européanisation reste limitée en comparaison à d'autres secteurs de l'action publique. Certes l'un et l'autre de ces deux processus conjoints se heurtent à de fortes résistances, dont la sempiternelle affirmation du lien entre culture et identité nationale n'est pas la moindre des manifestations. Il n'en reste pas moins cependant que les relations entre producteurs nationaux d'action culturelle publique n'ont sans doute jamais été aussi importantes - quand bien même on peut continuer de les juger insuffisantes. Les rencontres entre ministres européens chargés de ces questions et l'émergence de réseaux de professionnels en constituent en tout cas quelques indices. Dans ces relations sont confrontées des manières de voir et de traiter les problèmes culturels. On l'a vu notamment lors des débats sur l'“exception culturelle", puis à propos du prix du livre. Des formes institutionnelles tendent également, semble-t-il, à être échangées et donc "européanisées". La diffusion - ou au moins l'évocation - du "modèle français" dans les projets réalisés ou non de ministères de la Culture dans plusieurs pays européens illustre bien cette tendance renforcée au mimétisme ${ }^{2}$.

Ces confrontations et ces échanges rendent plus que jamais pertinente et nécessaire une approche comparée au niveau européen - engagée ici avec le cas des pays de l'Europe du Sud. La comparaison est en effet rendue plus pertinente du fait que la mise en relation de situations nationales est désormais réalisée en pratique, dans des relations effectives, et ne constitue plus seulement le résultat inévitablement artificiel d'un acte décisoire du chercheur. La comparaison s'avère de plus nécessaire pour qui veut comprendre les conditions d'émergence - et donc aussi les difficultés - de la coopération européenne en matière culturelle.

Dans une perspective comparée, le cas de la culture présente des difficultés mais aussi des intérêts particuliers. Notons simplement ici celles et ceux qui tiennent au fait que la culture soit instrumentée comme marqueur des identités nationales. Les conditions historiques de formation des États-nations européens ont imposé l'idée de "cultures nationales" spécifiques dont le patrimoine artistique et la galerie de portraits des 


\section{Pôle Sud $N^{\circ} 10$}

auteurs et artistes classiques viennent, entre autres, attester l'existence. Avec ces "cultures nationales" ce sont plus encore des conceptions nationales de la culture qui se sont plus ou moins - imposées. Il existe (ou existerait) des manières proprement française, allemande, etc. de définir la culture - ce que rappellent entre autres les premières pages de La civilisation des moeurs de Norbert Elias.

L'hypothèse est dès lors permise que les pouvoirs publics, qui ont fortement contribué à l'élaboration de ces conceptions nationales, les mettent en cuvre dans leur intervention culturelle, donnant de ce fait naissance à des formes de traitement public de la culture fortement différenciées d'un pays à l'autre. Et de fait, les différences sont très nettes - au moins jusqu'à la période récente où elles semblent $s$ 'atténuer - entre la Grande-Bretagne et l'Allemagne ou, pour citer des cas étudiés dans ce dossier, entre la France, l'Italie, L'Espagne le Portugal ou la Grèce, en ce qui concerne tant l'importance de l'investissement public (en particulier sur le plan financier) que les rapports entre acteurs privés et publics qui s'ensuivent, les priorités accordées selon les secteurs culturels (patrimoine, spectacle vivant, etc.), les relations entre administration centrale et institutions infra-étatiques, et jusqu'aux mots utilisés pour désigner ce sur quoi porte l'intervention - la qualification italienne des "biens culturels" est à cet égard exemplaire.

Ces différences accusées font la richesse et l'intérêt d'une comparaison qui, du fait notamment de l'origine de ces différences - les modes de formation des États, en particulier - peut contribuer à une mise en perspective bien au-delà des seules questions culturelles $^{3}$. Mais ces différences - que les textes présentés ici permettront pour une part de mesurer - forment aussi un obstacle à la comparaison. Jusqu'où est-on fondé en effet à utiliser la catégorie homogénéisante de politique culturelle pour rendre compte de situations fortement contrastées quant à son usage dans les différents pays voire quant à l'unification d'une "vraie" politique en la matière? C'est là une des questions que l'on souhaite ouvrir par l'analyse comparée plus qu'on ne la considère a priori comme résolue.

\section{Confronter des formes d'institutionnalisation}

Afin de prendre cette question au sérieux, sans toutefois qu'elle n'empêche tout bonnement l'analyse comparé, on a choisi de faire porter le regard sur les processus d'institutionnalisation de l'intervention publique en matière culturelle. On peut en effet repérer des processus d'institutionnalisation comparables d'un pays à l'autre; mais comparer ces processus, ce n'est pas présupposer que leurs issues soient forcément analogues. Les restituer permet précisément de comprendre ce qui rapproche et distingue les actions publiques qui en sont le produit.

Cet horizon commun des contributions présentées dans ce dossier se marque par plusieurs éléments que l'on retrouvera dans chacune d'entre elles ${ }^{4}$. Il s'agit tout d'abord d'une mise en perspective historique, permettant de rappeler les chemins divers qui ont mené aux politiques actuelles. Comment s'est peu à peu construit une politique propre au secteur culturel? Quelles sont les principales étapes de cette construction? Comment ce domaine d'intervention a-t-il été défini ? Telles sont quelques unes des questions posées. Une attention particulière 


\section{Politiques culturelles en Europe du sud}

a été, comme on le verra, accordée aux usages politiques de la culture au cours des périodes autoritaires qu'ont connues l'Italie, L'Espagne, le Portugal et la Grèce, non pour en faire une étude approfondie, mais pour évaluer leur place dans l'édification ultérieure de l'intervention culturelle publique.

Restituer l'institutionnalisation de cette intervention publique impliquait aussi d'être attentif à la création des institutions qui lui sont spécifiquement consacrées. Parmi elles, les départements ministériels occupent une place importante. On trouvera ainsi dans les différents articles des informations concernant leurs conditions de formation, leurs attributions, le découpage de leur secteur de compétence, leurs ressources, leurs structures. Leur lecture croisée permettra de percevoir l'étendue des possibilités qui se déploie entre le désormais ancien et fortement structuré ministère français de la Culture, l'expérience militante et encore très récente de son homologue portugais, et les péripéties de la création d'un ministère de la Culture en Italie. Mais ce ne sont là que des pistes générales, qu'il convient de compléter par des éléments plus spécifiques aux pays étudiés.

\section{Des politiques "méridionales"?}

L'hypothèse d'une convergence entre les différentes expériences nationales d'institutionnalisation de la culture en Europe du Sud supposerait, pour être solidement établie, un travail de comparaison autrement plus ample que celui auquel nous renvoyons ici le lecteur, notamment parce qu'il rendrait nécessaire une interrogation en retour sur les spécificités de l'Europe du Nord. On pointera néanmoins trois carac- téristiques qui reviennent fréquemment dans le discours sur la singularité méridionale des politiques publiques : leur rapport à une histoire singulière; la fragmentation institutionnelle; la politisation des enjeux d'action publique. Aucune de ces qualifications, on va le voir, ne permet de tracer des équivalences absolues de trajectoires. En ces matières, il ne peut être question que de convergences relatives, suffisamment notables toutefois pour apprécier, en retour, les conditions proprement sudeuropéennes d'une européanisation des affaires culturelles.

Le rapport des politiques culturelles sud-européenne à l'histoire est sans doute le plus évident, du moins en apparence. Chacun des quatre pays étudiés ici a connu, dans un passé plus ou moins récent, une expérience fasciste ou fascisante, dont il était tentant d'évaluer l'influence sur les conditions d'émergence des politiques culturelles. A l'examen, les choses sont sans doute plus complexes.

La première raison tient aux divergences entre politiques autoritaires quant au traitement de la culture au sein du régime. Ce constat, qui nous ramène d'ailleurs au contexte très contemporain qui est celui de l'étude de Cécile Bressat, ressort de la comparaison entre une politique très volontariste de transformation de la société par la culture, qui était celle du fascisme italien, et de l'expression beaucoup moins affirmée d'une politique culturelle autoritaire aprèsguerre en Espagne, en Grèce et au Portugal. On voit bien dans l'article d'Eduardo Prado Coelho combien les tentatives d'alignement sur cette version "haute" de la politique culturelle fasciste se heurtent à la résistance des élites gouvernementales elles-mêmes. 


\section{Pôle Sud $N^{\circ} 10$}

Bien au contraire, c'est sans doute plus dans le cadre même de l'assouplissement de ces régimes autoritaires finissants que l'on voit poindre une utilisation de la culture comme catégorie "légitimante" du régime : sa capacité à atténuer son image négative, comme on le voit dans la Grèce des colonels, dans la stratégie de permissivité sélective à l'égard de la Fondation Gulbenkian au Portugal, ou encore dans le maniement de la référence à la démocratisation culturelle d'un Malraux par... le ministre franquiste Fraga Iribarne.

Il reste que ces trajectoires singulières peuvent contribuer à expliquer la réticence que les régimes démocratisés ont affrontée à l'idée de fonder un véritable ministère et une politique culturelle en tant que telle. On en veut pour preuve la réalité du débat en Italie, où le projet de création d'un véritable ministère de la Culture ravive le spectre du Minculpop fasciste.

Ce thème de la fragmentation nous conduit enfin au troisième trait, souvent considéré comme distinctif, de l'Europe méridionale : la politisation des enjeux d'action publique et du rapport aux politiques publiques. Au-delà d'une discussion générale dont nous ne rendrons pas compte ici, la politisation de la culture renvoie au moins à deux dimensions.

La première se rapporte à la réalité des oppositions partisanes à propos des politiques culturelles légitimes. De ce point de vue, il semble bien que la prégnance d'une opposition droite-gauche trouve sa place en Europe du Sud sur la question du patrimoine. Celui-ci apparaît en effet comme un élément de mise en cohérence idéologique du côté des partis conservateurs, en ce qu'il réunit deux registres très différents. Le patri- moine repose d'abord sur une forte composante religieuse, dont la prégnance est encore très forte dans l'identité sud-européenne de la droite. L'idéologie de la conservation rejoint aussi l'antienne néo-libérale à laquelle se sont massivement reconverties ces mêmes formations, et selon laquelle seul le patrimoine n'entre pas dans le champ ouvert du marché, et mérite donc une intervention publique volontaire. Si cette double identité culturelle et politique se retrouve dans d'autres pays européens (en France au premier chef), elle aurait un sens particulier en Europe du Sud pour deux raisons : de l'importance matérielle du patrimoine et des charges liées à sa gestion, et de l'enracinement politique du fait religieux.

La seconde dimension de la politisation concerne le rapport des acteurs culturels à l'institution et, en filigrane, la question du clientélisme. De ce point de vue, si nos collègues constatent certains traits clientélistes dans la gestion des politiques culturelles, ceux-ci semblent moins provenir d'une quelconque identité sud-européenne que de caractéristiques fonctionnelles : défaut de structuration des politiques, fragmentation des organes et des instruments d'action. On reste circonspect, notamment à la lecture de certains témoignages et analyses des politiques culturelles de la France des années Lang, quant à l'irréductible singularité d'un rapport sudiste clientéliste à l'institution.

Au fond, le dernier trait que l'Europe du Sud pourrait représenter serait sans doute sa perméabilité aux échanges d'expériences et aux transferts d'instruments d'action. Il n'est qu'à observer l'importance que revêtent le "modele français" et certains de ses dispositifs (prix unique du livre, diversification des objets d'intervention publique, 


\section{Politiques culturelles en Europe du sud}

etc.), mais aussi de l'exemple britannique dans les débats d'orientation culturelle au Portugal, en Italie ou en Grèce. L'Europe du Sud pourrait ainsi apparaître comme un laboratoire de l'intégration européenne par les réponses originales qu' elle apporte par ses propres adaptations d'une pluralité d'instruments et de philosophies de l'action publique culturelle.

Afin d'engager une telle comparaison, des échanges entre chercheurs de pays différents ont été organisés, dont ce numéro de Pôle Sud marque une première étape ${ }^{5}$. On fait ainsi notre le principe désormais couramment admis dans la science politique française selon lequel l'impératif du travail de terrain, d'une part, et l'impossibilité pour des chercheurs isolés de le mener à bien dans plusieurs pays, d'autre part, impliquent la constitution de ce qu'il est convenu d'appeler un réseau, au sein duquel s'échangent points de vue et informations et se constituent des problématiques communes. Cela étant posé, il faut aussi admettre qu'il y a parfois loin de la coupe aux lèvres, et le dossier constitué ici, dans ses inévitables limites et imperfections, témoigne aussi des difficultés d'une telle entreprise... ne serait-ce que celle de trouver des chercheurs en sciences sociales ayant travaillé sur les politiques culturelles dans les pays choisis. $\mathrm{Ce}$ dossier constitue donc une première étape. C'est pour jeter les bases d'un développement de cette démarche comparatiste qu'a été privilégié un regard sur les trajectoires historiques, les processus d'institutionnalisation et la description des grandes orientations sectorielles.

\section{Mots-clés / Keywords}

Politique culturelle, comparatisme, institutionnalisation, Europe du Sud Cultural policy, comparatism, institutionalization, South Europe 